\title{
The Interaction between the Oropharyngeal Geometry and Aerosols via Pressurised Metered Dose Inhalers
}

\author{
T. Ehtezazi ${ }^{1, *}$, I. Saleem ${ }^{1}$, I. Shrubb ${ }^{2}$, D. R. Allanson ${ }^{3}$, I. D. Jenkinson ${ }^{3}$, C. \\ O’Callaghan $^{4}$ \\ ${ }^{1}$ School of Pharmacy \& Biomolecular Sciences, Liverpool John Moores University, Byrom \\ Street, Liverpool, L3 3AF, UK \\ ${ }^{2}$ AstraZeneca R\&D Charnwood, Pharmaceutical \& Analytical R\&D, LE11 \\ 5RH Loughborough, UK \\ ${ }^{3}$ School of Engineering, Liverpool John Moores University, Byrom Street, Liverpool, L3 \\ $3 \mathrm{AF}, \mathrm{UK}$ \\ ${ }^{4}$ Department of Infection, Inflammation and Immunity, University of Leicester, Leicester \\ LE2 7LX, UK
}

"Corresponding author: E-mail: t.ehtezazi@ljmu.ac.uk, Tel: (+44)151 231 2065, Fax: (+44) 1512312170. 


\section{Abstract}

Purpose. This study investigated the effect of oropharyngeal geometry on inhaled aerosol characteristics via pressurised metered dose inhalers (pMDIs), both with or without spacers. Methods. Seven adult oropharyngeal models with different centreline lengths, total volumes, and degree of constrictions were employed as induction ports for a laser diffraction particle size analyser and cascade impactor. Particle size change over time, mass median aerodynamic diameter (MMAD), average median volume diameter $\left(D_{\vee} 50\right)$, inhaled doses, and oropharyngeal depositions (percentage of the nominal dose) for aerosols via suspension and ultrafine pMDIs with or without spacers at $301 / \mathrm{min}$ airflow were determined.

Results. Variations in oropharyngeal geometry caused significant variations in inhaled particle size distributions, doses, oropharyngeal drug depositions, and particle size change over time when pMDIs were used without spacers. However, inhaled aerosol characteristics had marginal variations for the ultrafine pMDI plus large volume spacer (MMAD range: 0.69-0.78 $\mu \mathrm{m}, \mathrm{D}_{\mathrm{V}} 50$ range: $1.27-1.36 \mu \mathrm{m}$, inhaled dose range: $\left.46.46-52.92 \%\right)$. It was found that the amounts of inhaled aerosol particles with aerodynamic size of less than $0.83 \mu \mathrm{m}$ via pMDIs plus large volume spacer were slightly affected by the oropharyngeal geometry. Conclusion. Inhaling ultrafine aerosols via spacers may reduce the effect of oropharyngeal geometry on inhaled aerosol properties.

Key Words: Pressurised Metered Dose Inhalers; Ultrafine aerosols; Inter-subject inhaled dose variability; oropharyngeal models; acute asthma exacerbations 


\section{Introduction}

Pulmonary drug delivery has been employed not only for treatment of respiratory diseases, such as asthma, but also delivery of peptides such as insulin for systemic effects and vaccines for immunization [1]. Amongst the inhalers, pressurised metered dose inhalers (pMDIs) are used extensively by patients due to their portability, low airflow resistance, and generation of suitable aerosols independent of patient inspiratory flow rate. The presence of these properties has resulted in using pMDIs (with spacers) as first line drug delivery device in treatment of acute asthma exacerbations [2,3]. However, a subgroup of patients has been identified who had poor responses to inhaled drugs (corticosteroids and bronchodilators) via these devices $[2,4]$, which could not be attributed to the poor inhalation technique, as pMDIs were used with spacers. To achieve goals of therapy in these patients, increasing the drug dose was considered, but this resulted in increased drug systemic side effects [4], or the patients were required intense monitoring and hospitalisation [2]. Furthermore, it has been shown that variability in oropharyngeal drug deposition caused variability in amounts of drug reaching the lungs via inhalers [5-8], and consequently resulted in variable clinical responses [5]. Therefore, these observations suggest that reduction in the amount of drug reaching the lungs could have played an important role for poor responses to the inhalation therapy.

Attempts have been made to reduce the oropharyngeal drug deposition by increasing inhaler airflow resistance [8], and elongating the inhaler mouthpiece [9]. However, these approaches were not successful. This is because inhalers with a high airflow resistance were not suitable for young children and the elderly patients [10]. Furthermore, elongating inhaler mouthpiece was not sufficient to reduce significantly oropharyngeal drug deposition compared to the normal oropharyngeal drug depositions [9]. In fact, recent studies using oropharyngeal models have indicated that differences in the oropharyngeal geometries would cause variation in the amounts of drug delivered to the lungs via conventional suspension 
pMDIs with or without spacers [11,12]. However, ultrafine pMDIs (devices that generate aerosols with mass median aerodynamic diameter less than $1 \mu \mathrm{m}$ ) which have markedly different aerosol performance compared to conventional suspension pMDIs $[13,14]$ have not been investigated.

The primary goal of this study was to compare an ultrafine pMDI with a suspension pMDI with regard to the effect of oropharyngeal geometry on the inhaled aerosol particle size, particle size time profile, dose, and oropharyngeal drug deposition. In this study physiologically faithful oropharyngeal models were employed and spacers with different sizes were considered. A corticosteroid inhaler and a bronchodilator inhaler which are commonly used in treatment of acute asthma exacerbations were chosen. The secondary goal of this study was to estimate aerodynamic particle size, which would make the inhaled dose relatively independent of the oropharyngeal geometry.

\section{Material}

Brij®35 (polyoxyethylene lauryl ether) and beclometasone dipropionate were purchased from Sigma-Aldrich (Chemie GmbH, Steinheim, Germany). Glycerol was obtained from BDH Laboratory Supplies (Poole, England), salbutamol sulphate micronised powder was a gift from GlaxoSmithKline (Ware, UK), Decan 90 detergent solution was obtained from Decan Laboratories Ltd (Sussex, UK), and HPLC grade methanol was purchased from Fisher Scientific (Loughborough, UK). Salbutamol sulphate suspension pMDI (Ventolin ${ }^{\mathrm{TM}}$ Evohaler ${ }^{\mathrm{TM}}$,GlaxoSmithKline Ltd, London, UK, $100 \mu \mathrm{g}$ per actuation), and beclometasone dipropionate solution pMDI (Qvar ${ }^{\mathrm{TM}}$,Ivax Pharmaceuticals, London, UK, $50 \mu \mathrm{g}$ per actuation) were employed. 


\section{Methods}

\section{The Oropharyngeal Models and Add-on Spacers}

Three-dimensional reconstructions of the mouth and throat of healthy adult subjects inhaling at $30 \mathrm{l} / \mathrm{min}$ via the Bricanyl pMDI (AstraZeneca, Kings Langley, UK) and NebuChamber mouthpiece (AstraZeneca, Kings Langley, UK) were considered. These data were obtained in a previous study using magnetic resonance imaging (MRI) [15]. The subjects' age range was 23-35 years. In total, seven three-dimensional reconstructions were employed. For the purpose of this study, oropharyngeal shapes with different centreline lengths and configurations were used. The oropharyngeal geometries were ranked between 1 and 7 according to their volumes (by rank 1 being the smallest volume and 7 the largest one). Also, similar to a previous study [8], the oropharyngeal configurations were categorised into 3 groups. The grouping was based on the severity of the airway narrowing (due to the oropharyngeal posture) in the oropharynx section of the throat. The groups were:
A. Wide open space
B. Moderate narrowing
C. Marked constriction.

Figure 1A illustrates the three dimensional surface rendering of the reconstructed mouths and throats, their midsagittal sections, and designations (1C, 2C, 3A, 4A, 5A, 6B, 7B). Figure 1B depicts a typical head and neck MRI image illustrating the centreline in the mouth and throat, and the region of the airway (starting from the back of the upper lip to $2 \mathrm{~cm}$ below the vocal cords) that was considered to calculate the oropharyngeal volume. The midsagittal head and neck MRI images of the subjects, and cross sectional areas of the oropharyngeal reconstructions (along the centreline) are provided as on-line supplementary material. Table 1 presents the oropharyngeal lengths, volumes, and their designations. The oropharyngeal 
plastic (acrylnitrile-butadiene-styrene) models were prepared according to the previously reported method [16]. The $1 \mathrm{C}, 2 \mathrm{C}, 3 \mathrm{~A}$, and 5A models were employed in previous studies $[12,16]$. The inhalers were tested in this study had low airflow resistances similar to those that were used in the MRI study [15]; and also similar inspiratory airflow rates via the inhalers were employed. Furthermore, the circular shape and cross sectional diameter of the Qvar mouthpiece were similar to the shape and dimensions of the oral cavity inlets of $2 \mathrm{C}, 4 \mathrm{~A}$, 5A, and 6B models. Similarly, the rectangular shape and cross sectional diameter of the Ventolin Evohaler mouthpiece were comparable with shape and dimensions of the oral cavity inlets of $1 \mathrm{C}, 3 \mathrm{~A}$, and $7 \mathrm{~B}$ models. Therefore, marked differences in the oropharyngeal geometries due to switching from the original inhalers that were used in the MRI study [15] to those that were employed in this study were not expected.

The AeroTrach Plus ${ }^{\mathrm{TM}}$ spacer (Trudell Medical International) was used as a large valved holding chamber (large volume spacer, $149 \mathrm{ml}$ space volume). In addition, the Optimiser (Norton Healthcare and Glaxo-SmithKline Ltd, Harlow, UK,) was used with the Ventolin as small volume spacer. Furthermore, a high-density polyethylene tube with $2 \mathrm{~cm}$ internal diameter (2.2 cm outer diameter) and $8 \mathrm{~cm}$ length (denoted as "long tube") was used with the Qvar. To reduce the electrostatic charge in the spacers, these were soaked for 2 hours in $2 \%$ (w/v) Decan 90 solution and left to drip-dry.

The following inhaler devices were employed: the Qvar, Qvar with the large volume spacer, Qvar with the long tube, and Ventolin with the large volume spacer which had circular mouthpieces; and therefore these were used with the $2 \mathrm{C}, 4 \mathrm{~A}, 5 \mathrm{~A}$, and $6 \mathrm{~B}$ oropharyngeal models (which also had circular cross section at the inlet of the oral cavity part and diameter similar to the inhalers' mouthpieces). Combinations of the Ventolin pMDI with or without the Optimiser had rectangular mouthpiece shape; and therefore these were used with $1 \mathrm{C}, 3 \mathrm{~A}$, and $7 \mathrm{~B}$ models (which also had rectangular cross section at the inlet of the oral 
cavity part and diameter similar to the inhalers' mouthpieces). In this study it was possible to match commercially available ultrafine pMDI (the Qvar with circular mouthpiece) with the oropharyngeal models that also had circular oral cavity inlet. The rectangular mouthpiece of bronchodilator suspension pMDI necessitated using oropharyngeal models with rectangular oral cavity inlets. The matching of the inhalers with the corresponding oropharyngeal models was performed to ensure suitable connections between the inhalers and models. However, by considering employed airflow rate (30 1/min) and aerosol particle diameter (mostly less than $3 \mu \mathrm{m})$ in this study, based on a previous work, a considerable change in the oropharyngeal drug deposition due to variations in the mouthpiece diameter and shape was not expected [17].

\section{Laser Diffraction Particle Size Measurements}

A Sympatec HELOS BF/MAGIC ${ }^{\circledR}$ system (Sympatec GmbH, Clausthal-Zellerfeld, Germany) equipped with a modular inhaler adapter (INHALER ${ }^{\circledR}$ 2000) and R2 lens (size range from $0.25-87.5 \mu \mathrm{m}$ ) was used to obtain laser diffraction angles and intensities. The Fraunhofer model operated within the WINDOX 5 software was employed to calculate the particle size distributions of the samples. Aerosols were directed to the inhaler module either via an oropharyngeal model (connected to the inlet of the inhaler module from its upper trachea part) or by directly connecting the inhaler device to the instrument. In this study the counter flow was not used. However, the windows that the laser beam passed through were cleaned regularly.

To deliver aerosols to an oropharyngeal model, a pMDI with or without a spacer was connected to the oral cavity part of the corresponding model and sealed using flexible Parafilm M. Then the airflow through the inhaler device and oropharyngeal model was set to $301 /$ min and the device was actuated once. When the suspension pMDI was evaluated, the device was shaken before each actuation. The particle size measurements were performed at 
$1 \mathrm{~ms}$ time slices with trigger conditions of either optical concentration greater than $0.3 \%$, or real time duration of 0.2 seconds. As the duration of aerosol delivery via an inhaler with or without attaching to a model had a distribution, for simplicity, general trends are reported in this study. The airflow rate was set at 14 1/min when pMDIs were used with the large volume spacer and connected directly to the inhaler module (without using any oropharyngeal model). This allowed obtaining suitable number of sample data points. Based on a previous study, marked differences in the aerosol performances of the pMDIs used with the large volume spacer (reduced electrostatic charge) caused by switching the airflow rate from $30 \mathrm{l} / \mathrm{min}$ to 14 1/min were not expected [18]. Prior to each experiment, the oropharyngeal models were wetted with a solution of $0.7 \mathrm{~g}$ Brij 35 in $100 \mathrm{ml}$ of glycerol to simulate the wet mucosa that naturally occurs in the throat.

The particle size distributions were compared statistically by the average median volume diameter $D_{v} 50$, defined as $50 \%$ of the cumulative volume undersize (this parameter was indicated as $X_{50}$ by the manufacturer). The relative span, $\left(\mathrm{D}_{\mathrm{v}} 90-\mathrm{D}_{\mathrm{v}} 10\right) / \mathrm{D}_{\mathrm{v}} 50$, for each particle size distribution was calculated to present the dispersity of the distribution. Particle size measurements for each experimental setting were replicated six times.

\section{Aerodynamic Particle Size Measurements}

The oropharyngeal models using suitable adaptors were connected to the Next Generation Impactor (Copley Scientific, Nottingham, UK). Then, a glass microfibre filter at the outlet of the impactor was used to capture particles that were not collected by the impactor. A high capacity pump (Copley Scientific, Nottingham, UK) was used to draw air through the oropharyngeal models and impactor at 30 1/min. Based on previously published data, the impactor plates were not coated with any adhesive agents [19]. An inhaler device (pMDI with or without attaching to a spacer) was connected to the oral cavity of the 
respective model and the connection was sealed using Parafilm $M$ flexible film. When the required airflow through the device and model was established, the pMDI was actuated once and the airflow rate was maintained for 8 seconds. The suspension pMDI was shaken before each actuation. For each particle size measurement, the pMDIs were actuated 10 times. Then, the oropharyngeal model, spacer, impactor cups, and filter were washed with either distilled water for the salbutamol pMDI, or methanol/water mixture $(70 / 30 \% \mathrm{v} / \mathrm{v})$ for the beclometasone dipropionate pMDI. The amount of deposited drug in each section was determined using spectrophotometric analysis at $276 \mathrm{~nm}$ for salbutamol sulphate and $239 \mathrm{~nm}$ for beclometasone dipropionate from the relevant standard curves. Drug depositions within the impactor or oropharyngeal models are reported as percentage of nominal dose via the pMDIs. Oropharyngeal models before each aerosol deposition experiment were wetted by the corresponding washing solution to simulate the wet condition in the mouth and throat.

Since the oropharyngeal models were considered as the induction port for the impactor, then total amount of drug deposited in the impactor and attached filter was considered as the inhaled dose. The mass median aerodynamic diameter (MMAD) of aerosol particles for each experimental setting was calculated by plotting cumulative percentage of mass less than stated aerodynamic diameter (probability scale) versus aerodynamic diameter (log scale). Each deposition study was replicated six times. The experiments were performed at the local ambient conditions (typically $20^{\circ} \mathrm{C}$ temperature and $70 \%$ relative humidity). In the Result section the Qvar pMDI is referred as the ultrafine pMDI, and the Ventolin Evohaler pMDI as the suspension pMDI.

\section{Statistical Analysis}

Kruskal-Wallis tests followed by two-tailed Mann-Whitney U-tests for all cases were conducted. Then, by considering total number of comparisons, the Bonferroni correction was 
applied to the $\alpha$ level. Therefore, as the number of comparisons was 6 for each experimental setting in the group of $2 \mathrm{C}, 4 \mathrm{~A}, 5 \mathrm{~A}$, and $6 \mathrm{~B}$ models, the significance level for this group was considered as $P<0.008$. Similarly, since the number of comparisons was 3 for each experimental setting in the group of $1 \mathrm{C}, 3 \mathrm{~A}$, and $7 \mathrm{~B}$ models, the significance level was set as $P<0.016$. 


\section{Results}

\section{Particle Size Analysis}

\section{Laser Diffraction}

Figure 2 presents cumulative volume percent size distribution curves of aerosol particles at the exit of oropharyngeal models via the inhalers. In the figures, representative particle size distributions via the inhalers without using an oropharyngeal model are also plotted. It can be seen that particle size distributions were affected considerably by the oropharyngeal geometry when pMDIs were used alone (Figures $2 \mathrm{~A}$ and $2 \mathrm{~B}$ ), or the suspension pMDI with spacers (Figures 2C and 2D). When the large volume spacer was used with the ultrafine pMDI, the deviation from the original particle size distribution was minimal (Figure 2E).

Figure 3 illustrates particle size distribution parameters, $D_{\mathrm{V}} 10, D_{\mathrm{V}} 50, D_{\mathrm{V}} 90$, and span changes over time. It can be seen that when the oropharyngeal models were used with pMDIs only (Figures 3A, 3B, and 3C), duration of aerosol delivery was longer for the ultrafine pMDI than the suspension formulation. This may be explained due to entrapping of ultrafine aerosol particles in air recirculations (within the models) for a longer time than larger aerosol particles via the suspension formulation. Also, within each formulation, the duration of aerosol delivery was increased by increasing the oropharyngeal volume. Furthermore, all particle size distribution parameters changed significantly over time for models that had constrictions in the oral cavity (the $1 \mathrm{C}, 2 \mathrm{C}, 6 \mathrm{~B}$, and $7 \mathrm{~B}$ models). Taking pMDI formulation into account, decrease in particle size was more significant for the ultrafine pMDI (contained alcohol) than the suspension formulation.

The emission of aerosols with relatively constant particle size distribution via the oropharyngeal models with wide openings in the oral cavity (the $4 \mathrm{~A}$ and $5 \mathrm{~A}$ models in Figures $3 \mathrm{~A}$ and 3B) by using the ultrafine pMDI may be explained by rapid ventilation of the 
models and consequently faster evaporation of the propellant and excipient. However, a relatively steady state situation in particle size was observed around 2 seconds after actuation for models with large oropharyngeal volumes (the 5A and 6B models). Particle size change over time for pMDIs without connecting to the models did not follow the above patterns (data not shown).

Using the large volume spacer plus pMDIs alleviated particle size change over time for $\mathrm{D}_{\mathrm{v}} 50$ (Figure 3F) and $\mathrm{D}_{\mathrm{v}} 90$ (Figure $3 \mathrm{G}$ ), but not for $\mathrm{D}_{\mathrm{v}} 10$ (Figure $3 \mathrm{E}$ ) values for aerosols that pass through the models. Similar trends (Figures 3E-3G) were also observed for aerosols via the pMDIs plus the large volume spacer only (without connecting to models). It can be seen from Figure $3 E$ that for these aerosols $D_{v} 10$ values initially increased then decreased. This may be due to saturation of the laser measuring chamber with the propellant and excipient; and consequently delaying evaporation of aerosol particles. Similarly, gradual evaporation of propellants and excipients from the aerosol particles within the models might cause a gradual decline in particle size when the models were employed.

The average volume median diameters $\left(\mathrm{D}_{\mathrm{v}} 50\right)$ of the aerosol particles via the pMDIs with or without spacers are illustrated in Figure 4A. In this figure data are presented as ascending oropharyngeal volume on the $\mathrm{x}$-axis. It can be seen from using the ultrafine pMDI without a spacer $D_{v} 50$ decreases significantly from $1.24 \pm 0.09 \mu \mathrm{m}$ to $0.82 \pm 0.01 \mu \mathrm{m}$ as the oropharyngeal volume increases from 53.4 to $68.4 \mathrm{~cm}^{3}$ (oropharyngeal models: $2 \mathrm{C}, 4 \mathrm{~A}$, and $5 A)$. However, average $D_{v} 50$ increases significantly to $1.10 \pm 0.13 \mu \mathrm{m}$ despite increasing the oropharyngeal volume $\left(75.1 \mathrm{~cm}^{3}\right)$ for the $6 \mathrm{~B}$ model. A similar trend in average $\mathrm{D}_{\mathrm{v}} 50$, but with less severity can also be seen for the ultrafine pMDI that was used with the long tube. This observation may be explained by referring to Figures $3 \mathrm{~A}$ to $3 \mathrm{C}$ indicating that the presence of constrictions in the oral cavity might delay evaporation of the propellant and 
excipient, which resulted in initial larger aerosol particles emitting from the model; and this increased the average value of $D_{v} 50$.

Using the ultrafine pMDI with the large volume spacer increased average $D_{v} 50$ compared to the ultrafine pMDI without using the spacers (Figure 4A), but the variability of these values between the oropharyngeal models decreased $(1.27 \pm 0.06 \mu \mathrm{m}$ to $1.36 \pm 0.13$ $\mu \mathrm{m}$ ). In contrast, average $\mathrm{D}_{\mathrm{v}} 50$ changed considerably for the suspension pMDI (with or without spacers) as a function of total oropharyngeal volume and presence of constrictions in the oral cavity (Figure 4A).

\section{Aerodynamic Particle Size}

Cumulative mass aerodynamic distribution curves for aerosol particles that passed through the models via the inhalers are illustrated in Figure 5. A clear effect of oropharyngeal geometry on the distribution curves can be seen when pMDIs used without spacers (Figure 5A for the ultrafine pMDI, and 5C for the suspension pMDI). Using the large

volume spacer (Figure 5B and 5C) or the small volume spacer with the suspension formulation (Figure 5E) reduced the effect of oropharyngeal geometry on aerodynamic particle size distributions (at least up to $90 \%$ cumulative mass). The data in Figure 5 also show a non-linear relationship between cumulative mass under size and aerodynamic particle size in the probability-log scale, for aerosols that passed through the models, in particular for the ultrafine pMDI.

Particle deposition distributions within the impactor for the pMDIs used with the large volume spacer are illustrated in Figure 6 (Figure 6A for the ultrafine pMDI and 6B for the suspension pMDI). It can be seen that amount of inhaled aerosol particles with aerodynamic diameter less than $0.83 \mu \mathrm{m}$ (stage 7 , MOC and filter) became relatively independent of the oropharyngeal geometry. 
Estimated mass median aerodynamic particle diameters for aerosols via the inhalers attached to the models are presented in Figure 4B. Significant differences between MMAD values were found for the ultrafine pMDI without spacer (MMAD range: $0.41 \pm 0.04 \mu \mathrm{m}$ to $0.61 \pm 0.04 \mu \mathrm{m}, P<0.008$ ), salbutamol pMDI with the large volume spacer (MMAD range: $1.86 \pm 0.18$ to $2.05 \pm 0.13 \mu \mathrm{m} P<0.008)$, and salbutamol pMDI with the small volume spacer (MMAD range: $1.86 \pm 0.07 \mu \mathrm{m}$ to $2.05 \pm 0.04 \mu \mathrm{m}, P<0.016$ ). However, the differences in MMAD values of the models for the salbutamol without spacer, despite the large variations, did not reach the significance level (range: $1.73 \pm 0.12 \mu \mathrm{m}$ to $1.85 \pm 0.13$ $\mu \mathrm{m})$. On the other hand, using the ultrafine pMDI with the large volume spacer resulted in less variation in the MMAD values (MMAD range: $0.69 \pm 0.03 \mu \mathrm{m}$ to $0.78 \pm 0.02 \mu \mathrm{m}$ ) with no significant differences amongst those.

\section{Inhaled Dose and Oropharyngeal Drug Deposition}

The inhaled doses and oropharyngeal drug depositions, as percentage of the nominal dose, via the pMDIs with or without spacers are shown in Figure 7. In this figure data are presented as ascending oropharyngeal volume on the x-axis. A general positive correlation can be seen between volume of the oropharyngeal model and inhaled dose (Figure 7A) for the ultrafine pMDI without spacer $(15.99 \pm 4.95 \%$ to $42.50 \pm 3.68 \%)$, and salbutamol pMDI with or without spacers. Statistical analysis showed significant differences amongst those values. However, inhaled doses for the ultrafine pMDI with the large volume spacer despite a small increase $(46.46 \pm 2.77 \%$ to $52.92 \pm 4.92 \%)$ were relatively independent of the oropharyngeal geometry and showed no significant differences amongst the models. Data in Figure 7A also indicate that inhaled doses via the suspension pMDI plus the large volume spacer were comparable with those through the small volume spacer. 
Increasing oropharyngeal volume reduced oropharyngeal drug deposition for the ultrafine pMDI with or without the large volume spacer, and suspension pMDI with the large volume spacer (Figure 7B). However, oropharyngeal drug depositions via the suspension pMDI with or without the small volume spacer were dependent on the oropharyngeal volume and presence of constrictions within the airway. Drug deposition, as percentage of the nominal dose, within the large volume spacer was $14.94 \pm 1.32 \%$ for the ultrafine pMDI, and $64.79 \pm 4.35 \%$ for the suspension pMDI. 


\section{Discussion}

The results of this study suggest that inhaled doses of aerosol particles with aerodynamic size less than $0.83 \mu \mathrm{m}$ from large volume spacers at rate of $30 \mathrm{l} / \mathrm{min}$ would not be affected significantly by the oropharyngeal geometry. Also, the presence of constrictions in the oral cavity may affect evaporation rate of aerosol particles via pMDIs.

Treatment with high and repeated doses of brochodilators and corticosteroids in management of acute asthma exacerbations have been indicated in the literature [20,21]. Delivering high and less variable inhaled doses of these drugs would be crucial in an effective treatment of acute asthma exacerbations. Therefore, based on the results of this study, to achieve high and less variable lung doses, development of ultrafine or nanosuspension pMDI formulations should be expanded $[22,23]$.

The results of this study further demonstrate that although ultrafine pMDIs may produce aerosol particles with MMAD of $1 \mu \mathrm{m}$ [14], time and space should be given for evaporation of propellant and cosolvent from the initial generated aerosol particles. Then the inhaled dose may become independent of oropharyngeal geometry. It should be noted that in this study the ambient conditions (humidity and temperature) were used for the inhaled air. Whereas the results of this study may not be valid if air with high level of humidity is inhaled which may increase the size of inhaled particles [24]. Furthermore, as particle size may change due to hygroscopic growth in the lungs [25], then depending on the change in the particle size, despite the similarity of inhaled doses, the same regions of the lungs may not be targeted [26].

The results of this study agree well with a previous in vitro study showing a negative correlation between total oropharyngeal volume and aerosol deposition in the throat via a suspension pMDI [11]. In addition, the current study shows that the presence of constrictions should be considered. Since smaller throats with wide openings in the airway may result in 
similar aerosol depositions as do larger throats but with constrictions. Furthermore, the relationship between the total oropharyngeal volume and inhaled dose, or oropharyngeal drug deposition may be eliminated if ultrafine aerosols are inhaled via a large volume spacer at 30 $1 / \min$

Despite the important role of corticosteroids in management of acute asthma exacerbations, a study has found no benefit of doubling inhaled corticosteroid amounts in the management plan [27]. This observation may be partly explained by the results of this study that as the inhalers in the above study were suspension pMDIs, then the inhaled doses might have been extensively affected by the oropharyngeal geometry and posture.

The results of this study regarding variation in the oropharyngeal aerosol deposition via pMDIs may be applicable to adult subjects with stable asthma, as differences in oropharyngeal aerosol depositions between these asthmatic and healthy adult subjects have not been shown before [28]. However, it should be noted that the oropharyngeal models employed in this study were based on healthy adult subjects. This may not completely represent patients with acute asthma exercitations. As it seems impossible to determine the oropharyngeal configurations of these patients using conventional methods such as MRI, then it was anticipated that employing oropharyngeal models with different configurations would illustrate the possible range of oropharyngeal geometries that may occur in these patients. Additionally, it may be argued that elements other than suitable particle size distribution and dose of aerosols are required in an effective treatment of acute asthma exacerbations. Therefore, clinical studies will be required to establish the results of the current study.

The results of this study are also in good agreement with data from clinical studies showing large intra-subject and inter-subject variations of lung doses for aerosol particles with MMAD $>2 \mu \mathrm{m}$ [29-32]. In addition, the results of this study agree with the data of a clinical study showing high lung doses (approximately $58 \%$ of the ex-actuator dose) with 
little variability via the Qvar with a large volume spacer in children aged 5 to 17 years old [33]. Age dependent drug lung deposition via a suspension pMDI plus spacer has shown before [34].

Another limitation of this study is comparing the aerosol performances of two pMDI formulations with different actuator designs. As it has been shown that the actuator design such as the orifice size could have effect on the plume geometry [35], then the results of this study may not be valid if significant changes are applied to the actuators or formulations of employed pMDIs.

In conclusion, the present study suggests that delivery of aerosol particles with MMAD less than $0.83 \mu \mathrm{m}$ to the lungs via large volume spacers at $30 \mathrm{l} / \mathrm{min}$ inhalation flow rate would not be affected significantly by the variations in the oropharyngeal geometry. The results of this study are in good agreement with clinical data. Therefore, in formulation of pMDIs, ability of a product to generate ultrafine aerosol particles may be considered an important feature when fast and precise amount of inhaled drug is necessary.

\section{Acknowledgment}

We would like to take this opportunity and express our gratitude to Sympatec Ltd, Waterfold House, Bury, BL9 7BR for providing use of the Sympatec HELOS BF/MAGIC ${ }^{\circledR}$ system with the Inhaler 2000 module to perform this study. We would like to thank $\mathrm{Mr}$ Jonathan Veal and Anthony Dunmore for their technical assistance. The original MRI data to manufacture the oropharyngeal models was obtained from a study that was sponsored by AstraZeneca R\&D Charnwood, and this study was reported previously [15]. 


\section{Figure Legends}

Figure 1: A) Three-dimensional reconstructions of the oropharyngeal geometries that were employed in this study, the $2 \mathrm{C}, 4 \mathrm{~A}, 5 \mathrm{~A}$, and $6 \mathrm{~B}$ are oropharyngeal geometries by inhaling via the circular mouthpiece; and the 1C, 3A, and 7B are oropharyngeal geometries via the rectangular mouthpiece. In this panel the midsaggital sections of the reconstructed geometries are also presented. B) A typical midsaggital MRI image of a subject inhaling via an inhaler, illustrating different regions of the mouth and throat, and the region that was considered to calculate the oropharyngeal volume.

Figure 2: Cumulative undersize volume percent particle size distributions of aerosol particles that passed the oropharyngeal models via the ultrafine pMDI alone (panel A), suspension pMDI alone (panel B), suspension pMDI with the large volume spacer (panel C), suspension pMDI with the small volume spacer (panel D), and ultrafine pMDI with the large volume spacer (panel E). In these figures typical particle size distributions via the inhalers only (without attaching to a model) are presented by black filled symbols. Error bars present standard deviations $(n=6)$.

Figure 3: Over time change of particle size distribution parameters, $D_{\vee} 10, D_{\vee} 50, D_{V} 90$, and span via inhalers. Panels A to D are for pMDIs without spacers, and $\mathrm{E}$ to $\mathrm{H}$ for pMDIs with the large volume spacer. Open circular symbols show the $1 \mathrm{C}$ geometry, filled circular symbols show the 2C geometry, open square symbols depict the $3 \mathrm{~A}$ geometry, filled triangle symbols depict the 4A geometry, filled square symbols illustrate the 5A geometry, filled diamond symbols present the 6B geometry, and open diamond symbols illustrate the $7 \mathrm{~B}$ geometry. In Figure $\mathrm{E}$ to $\mathrm{H}$ grey curves present particle size distributions for the pMDIs with the large volume spacer but without attaching to an oropharyngeal model. Open grey circle 
symbols depict the suspension pMDI, and filled grey diamond symbols show the ultrafine pMDI. For the grey plots, the airflow was set at 14 1/min.

Figure 4: Panel A: average median volume diameters, $D_{v} 50$, of aerosol particles that passed through the models via the ultrafine pMDI without a spacer, with the large volume spacer, and with the long tube, also the salbutamol pMDI without a spacer, with the large volume spacer, and the small volume spacer (the Optimiser). Panel B: MMAD of the aerosol particles that passed through the models via the above inhalers, apart from the ultrafine pMDI with the long tube. Dotted white bars show the $1 \mathrm{C}$ model, horizontally hatched bars show the 2C model, chequered bars indicate the 3A model, diagonally hatched bars depict the 4A model, vertically hatched bars present the 5A model, white bars show the $6 \mathrm{~B}$ model, and grey bars designate the 7B model. In each device category, data is presented as ascending oropharyngeal volume (from left to right). Horizontal brackets show significant differences between pairs. Error bars present standard deviations $(n=6)$.

Figure 5: Cumulative mass percent less than stated size distributions in probability-log scale for aerosol particles passed through the models via the ultrafine pMDI alone (Panel A), ultrafine pMDI with the large volume spacer (Panel B), salbutamol pMDI alone (Panel C), salbutamol pMDI with the large volume spacer (Panel D), and salbutamol pMDI with the Optimiser (Panel E). Open circular symbols show the 1C geometry, filled circular symbols show the $2 \mathrm{C}$ geometry, open square symbols depict the $3 \mathrm{~A}$ geometry, filled triangle symbols depict the 4A geometry, filled square symbols illustrate the 5A geometry, filled diamond symbols present the 6B geometry, and open diamond symbols illustrate the 7B geometry $(n=$ 6). 
Figure 6: Drug deposition distributions within the impactor for aerosols passed through the models via the ultrafine pMDI (panel A) and suspension pMDI (panel B) used with the large volume spacer. Horizontally hatched bars show the $2 \mathrm{C}$ model, diagonally hatched bars depict the $4 \mathrm{~A}$ model, vertically hatched bars present the $5 \mathrm{~A}$ model, and white bars show the $6 \mathrm{~B}$ model. Error bars present standard deviations $(n=6)$.

Figure 7: Inhaled dose (panel A) and oropharyngeal drug deposition (panel B) as percentage of the nominal dose via the inhalers. Dotted white bars show the 1C model, horizontally hatched bars show the $2 \mathrm{C}$ model, chequered bars indicate the $3 \mathrm{~A}$ model, diagonally hatched bars depict the 4A model, vertically hatched bars present the 5A model, white bars show the 6B model, and grey bars designate the 7B model. In each device category, data is presented as ascending oropharyngeal volume (from left to right). Horizontal brackets indicate significant differences between pairs. Error bars present standard deviations $(n=6)$.

On-line Supplementary Material: A) Midsaggital magnetic resonance images of subjects while inhaling via inhalers. B) Cross sectional area distributions of the $2 \mathrm{C}, 4 \mathrm{~A}, 5 \mathrm{~A}$, and $6 \mathrm{~B}$ oropharyngeal geometries via a circular mouthpiece and low airflow resistance device. C) Cross sectional area distributions of the $1 \mathrm{C}, 3 \mathrm{~A}$, and $7 \mathrm{~B}$ oropharyngeal geometries via a rectangular mouthpiece and low airflow resistance device. Open circular symbols present the $1 \mathrm{C}$ geometry, filled circular symbols show the $2 \mathrm{C}$ geometry, open square symbols depict the 3A geometry, filled triangle symbols depict the 4A geometry, filled square symbols illustrate the 5A geometry, filled diamond symbols present the 6B geometry, and open diamond symbols illustrate the 7B geometry. 


\section{Reference:}

1. B. L. Laube. The expanding role of aerosols in systemic drug delivery, gene therapy, and vaccination. Respir. Care;50:1161-76 (2005).

2. Karpel JP, Aldrich TK, Prezant DJ, Guguchev K, Gaitan-Salas A, Pathiparti R. Emergency treatment of acute asthma with albuterol metered-dose inhaler plus holding chamber: how often should treatments be administered? Chest 112:348-356 (1997).

3. M. B. Dolovich, R. C. Ahrens, D. R. Hess, P. Anderson, R. Dhand, J. L. Rau, G. C. Smaldone, and G. Guyatt; American College of Chest Physicians; American College of Asthma, Allergy, and Immunology. Device selection and outcomes of aerosol therapy: Evidence-based guidelines: American College of Chest Physicians/American College of Asthma, Allergy, and Immunology. Chest 127:335-371 (2005).

4. S. J. Szefler, R. J. Martin, T. S. King, H. A. Boushey, R. M. Cherniack, V. M. Chinchilli, T. J. Craig, M. Dolovich, J. M. Drazen, J. K. Fagan, J. V. Fahy, J. E. Fish, Ford JG, Israel E, Kiley J, Kraft M, Lazarus SC, Lemanske RF Jr, Mauger E, S. P. Peters, and C. A. Sorkness; Asthma Clinical Research Network of the National Heart Lung, and Blood Institute. Significant variability in response to inhaled corticosteroids for persistent asthma. J. Allergy Clin. Immunol. 109:410-8 (2002).

5. L Borgström, E Derom, E Ståhl, E Wåhlin-Boll, R Pauwels. The inhalation device influences lung deposition and bronchodilating effect of terbutaline. Am. J. Respir. Crit. Care Med.153:1636-1640 (1996).

6. L Borgström, B Olsson, L Thorsson. Degree of throat deposition can explain the variability in lung deposition of inhaled drugs. J. Aerosol Med. 19:473-483 (2006).

7. Dunbar C, Scheuch G, Sommerer K, DeLong M, Verma A, Batycky R. In vitro and in vivo dose delivery characteristics of large porous particles for inhalation. Int. J. Pharm. 245:179-189 (2002).

8. K. Svartengren, P. Lindestad, M. Svartengren, K. Philipson, G. Bylin, and P. Camner. Added external resistance reduces oropharyngeal deposition and increases lung deposition of aerosol particles in asthmatics. Am. J. Respir. Crit. Care Med. 152:3237 (1995).

9. K. Svartengren, M. Anderson, M. Svartengren, K. Philipson, and P. Camner. Oropharyngeal deposition of 3.5 microns particles inhaled through an elongated mouthpiece. Eur. Respir. J. 9:1556-1559 (1996).

10. De Boeck K, Alifier M, Warnier G. Is the correct use of a dry powder inhaler (Turbohaler) age dependent? J. Allergy Clin. Immunol. 103:763-767(1999).

11. P. K. Burnell, L. Asking, L. Borgström, S. C. Nichols, B. Olsson, D. Prime, I. Shrubb. Studies of the human oropharyngeal airspaces using magnetic resonance imaging IV -the oropharyngeal retention effect for four inhalation delivery systems. J. Aerosol Med. 20:269-281 (2007).

12. T. Ehtezazi, D. R. Allanson, I. D. Jenkinson, and C. O'Callaghan. Effect of oropharyngeal length in drug lung delivery via suspension pressurized metered dose inhalers. Pharm. Res. 23:1364-1372 (2006).

13. H. M. Janssens, J. C. De Jongste, W. C. Hop, and H. A. Tiddens. Extra-fine particles improve lung delivery of inhaled steroids in infants: a study in an upper airway model. Chest 123:2083-2088 (2003).

14. C. L. Leach, P. J. Davidson, B. E. Hasselquist, and R. J. Boudreau. Lung deposition of hydrofluoroalkane-134a beclomethasone is greater than that of chlorofluorocarbon fluticasone and chlorofluorocarbon beclomethasone : a cross-over study in healthy volunteers. Chest 122: 510-516 (2002). 
15. T. Ehtezazi, M. A. Horsfield, P. W. Barry, and C. O'Callaghan. Dynamic change of the upper airway during inhalation via aerosol delivery devices. J. Aerosol Med. 17:325-334 (2004).

16. T. Ehtezazi, K. W. Southern, D. Allanson, I. Jenkinson, and C. O'Callaghan. Suitability of the upper airway models obtained from MRI studies in simulating drug lung deposition from inhalers. Pharm. Res. 22:166-170 (2005).

17. TC Lin, PN Breysse, BL Laube, DL Swift. Mouthpiece diameter affects deposition efficiency in cast models of the human oral airways. J. Aerosol Med. 14:335-341 (2001).

18. J.H. Wildhaber, S.G. Devadason, E. Eber, M.J. Hayden, M.L. Everard, Q.A. Summers, P.N. LeSouëf. Effect of electrostatic charge, flow, delay and multiple actuations on the in vitro delivery of salbutamol from different small volume spacers for infants. Thorax 51:985-988 (1996).

19. P.J. Mitchell, M. W. Nagel, K. J. Wiersema, and C. C. Doyle. Aerodynamic particle size analysis of aerosols from pressurised metered dose inhalers: Comparison of Anderson 8-stage cascade impactor, next generation pharmaceutical impactor, and model 3321 aerodynamic particle sizer aerosol spectrometer. AAPS PharmSciTech 4:1-9 (2003).

20. B Volovitz, E Bilavsky, M Nussinovitch. Effectiveness of high repeated doses of inhaled budesonide or fluticasone in controlling acute asthma exacerbations in young children. J. Asthma. 45:561-567 (2008).

21. British Thoracic Society Scottish Intercollegiate Guidelines Network. British Guideline on the Management of Asthma. Thorax 63: iv1 - iv121 (2008).

22. B.K. Nyambura , I.W. Kellaway , K.M. Taylor. Insulin nanoparticles: stability and aerosolization from pressurized metered dose inhalers. Int J Pharm. 375:114-1122 (2009).

23. L Wu L, M Al-Haydari, SR da Rocha. Novel propellant-driven inhalation formulations: engineering polar drug particles with surface-trapped hydrofluoroalkane-philes. Eur. J. Pharm. Sci. 33:146-158 (2008).

24. A. R. Martin, W. H. Finlay. The Effect of Humidity on the Size of Particles Delivered from Metered-Dose Inhalers. Aerosol Sci Tech 39:283-289 (2005).

25. TB Martonen, KA Bell, RF Phalen, AF Wilson, A Ho. Growth rate measurements and deposition modelling of hygroscopic aerosols in human tracheobronchial models. Ann Occup Hyg. 26:93-108 (1982).

26. AJ Hickey, TB Martonen. Behavior of hygroscopic pharmaceutical aerosols and the influence of hydrophobic additives. Pharm. Res. 10:1-7 (1993).

27. J. Garrett, S. Williams, C. Wong, and D. Holdaway. Treatment of acute asthmatic exacerbations with an increased dose of inhaled steroid. Arch. Dis. Child 79:12-17 (1998).

28. K Svartengren, $\mathrm{K}$ Philipson, $\mathrm{M}$ Svartengren, $\mathrm{M}$ Anderson, $\mathrm{P}$ Camner. Tracheobronchial deposition and clearance in small airways in asthmatic subjects. Eur. Respir. J. 9:1118-1122 (1996).

29. O. Aswania, S. Ritson, S. M. Iqbal, J. Bhatt, A. S. Rigby, and M. L. Everard. Intrasubject variability in lung dose in healthy volunteers using five conventional portable inhalers. J. Aerosol Med. 17:231-238 (2004).

30. L. Borgström, T. Bengtsson, E. Derom, and R. Pauwels. Variability in lung deposition of inhaled drug, within and between asthmatic patients, with a pMDI and a dry powder inhaler, Turbuhaler. Int. J. Pharm. 193:227-230 (2000). 
31. O. S. Usmani, M. F. Biddiscombe, and P. J. Barnes. Regional lung deposition and bronchodilator response as a function of beta2-agonist particle size. Am. J. Respir. Crit. Care Med. 172:1497-1504 (2005).

32. S. H. Mazhar, N. E. Ismail, D. A. Newton, and H. Chrystyn. Relative lung deposition of salbutamol following inhalation from a spacer and a Sidestream jet nebulizer following an acute exacerbation. Br. J. Clin. Pharmacol. 65:334-337 (2008).

33. C. M. Roller, G. Zhang, R. G. Troedson, C. L. Leach, P. N. Le Souëf, and S. G. Devadason. Spacer inhalation technique and deposition of extrafine aerosol in asthmatic children. Eur. Respir. J. 29:299-306 (2007).

34. J Onhøj, L Thorsson, H Bisgaard. Lung deposition of inhaled drugs increases with age. Am. J. Respir. Crit. Care Med. 162:1819-1822 (2000).

35. H Smyth, AJ Hickey, G Brace, T Barbour, J Gallion, J Grove. Spray pattern analysis for metered dose inhalers I: Orifice size, particle size, and droplet motion correlations. Drug Dev. Ind. Pharm. 32:1033-41(2006). 

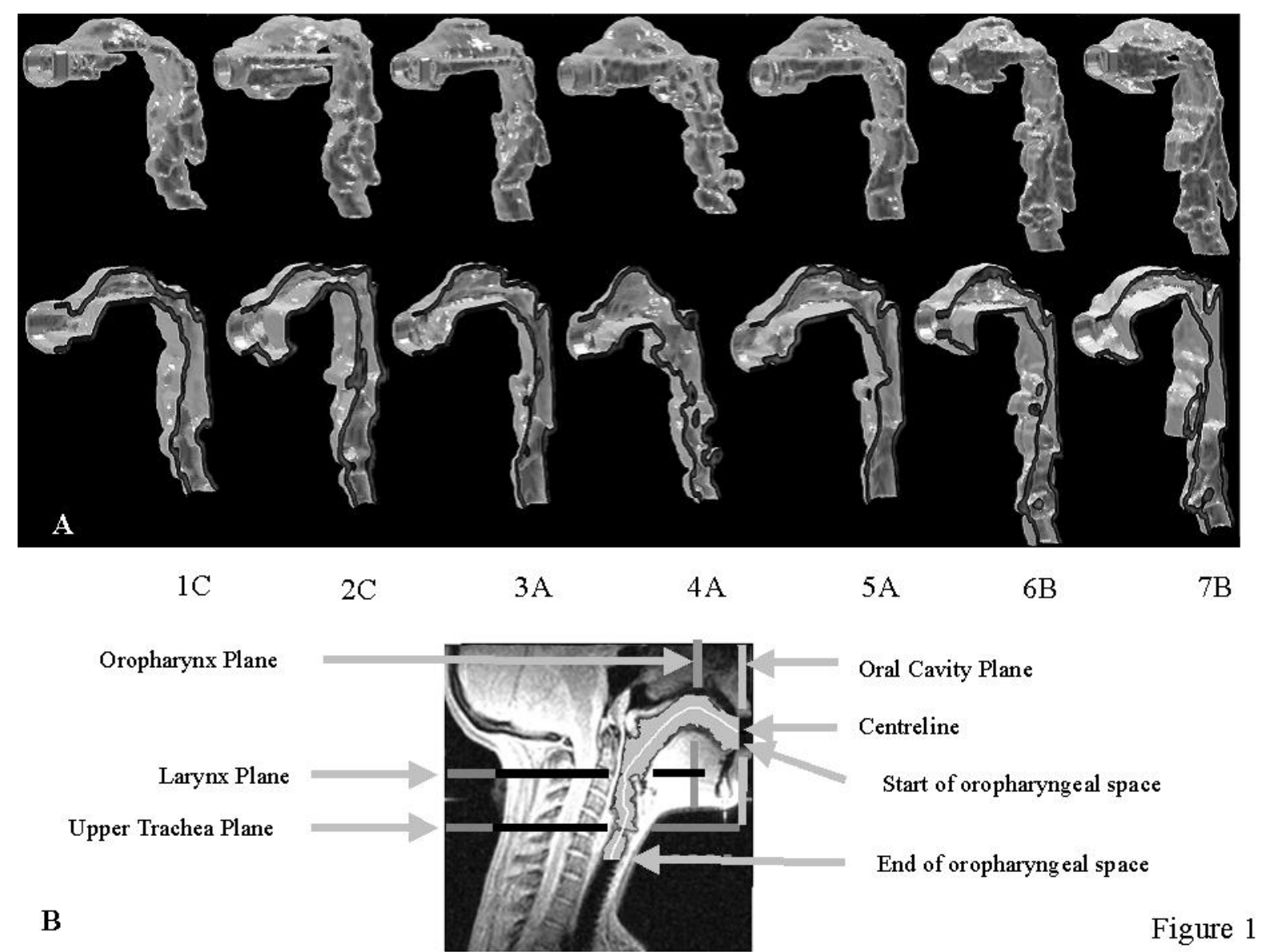
Figure 2

A
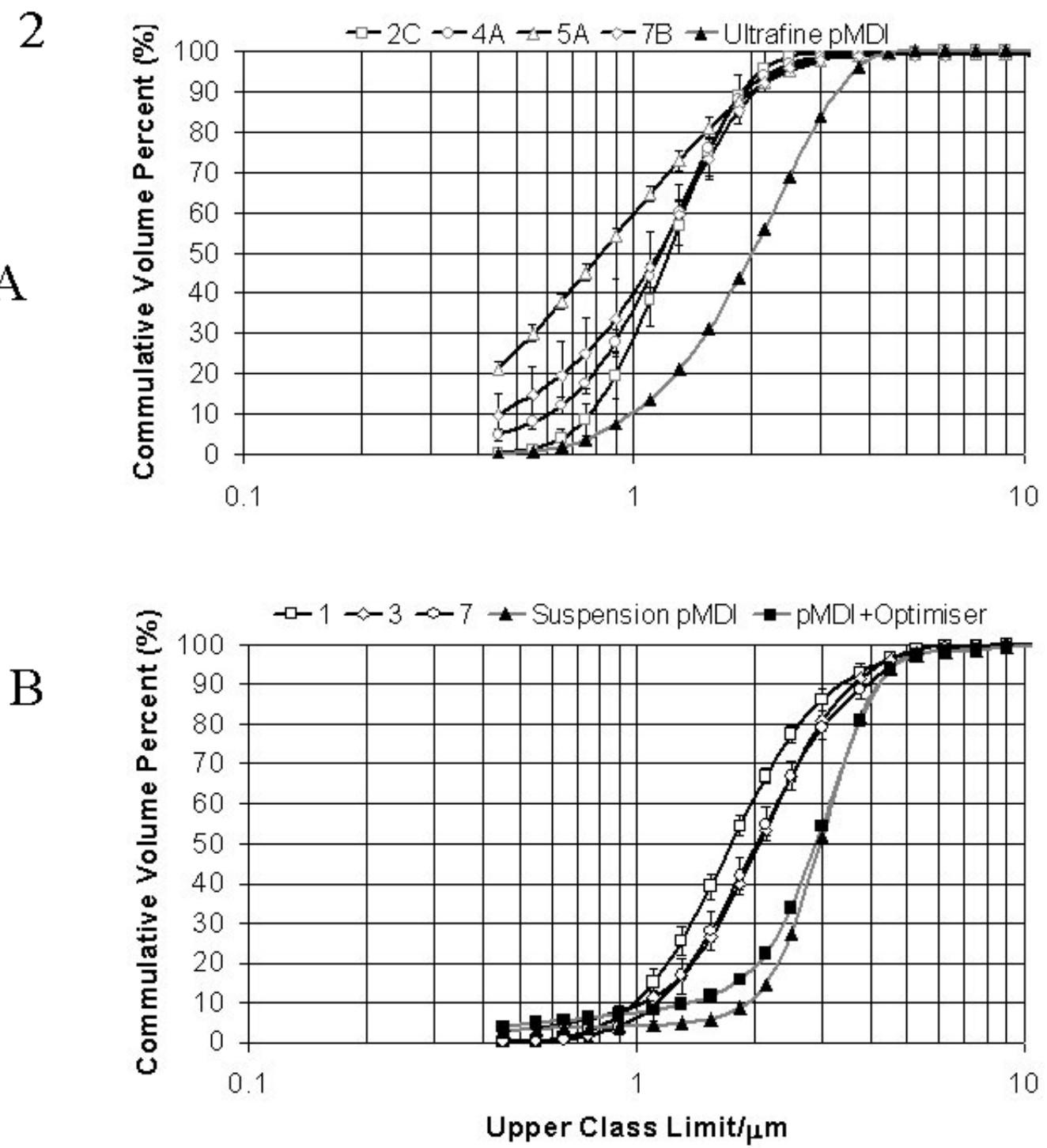
Figure $2 \lesssim 100 \quad-\square-2-4-5-5 \curvearrowleft 6-$ Salbutamol $\mathrm{pMD}$ +spacer
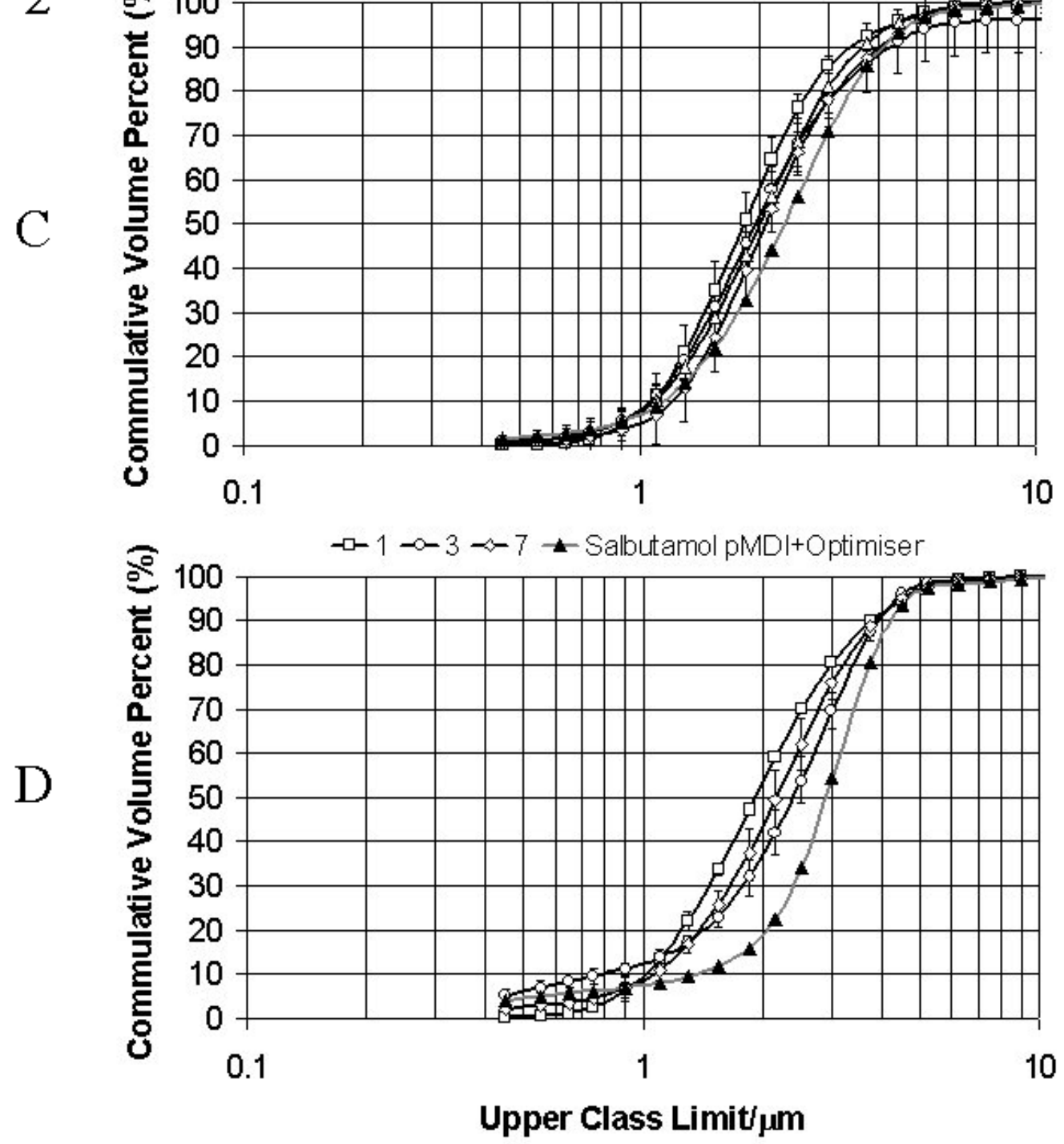
Figure 3

$-1 \mathrm{C}$ Suspension pMDI

$-2 \mathrm{C}$ Ultrafine $\mathrm{PMDI}$
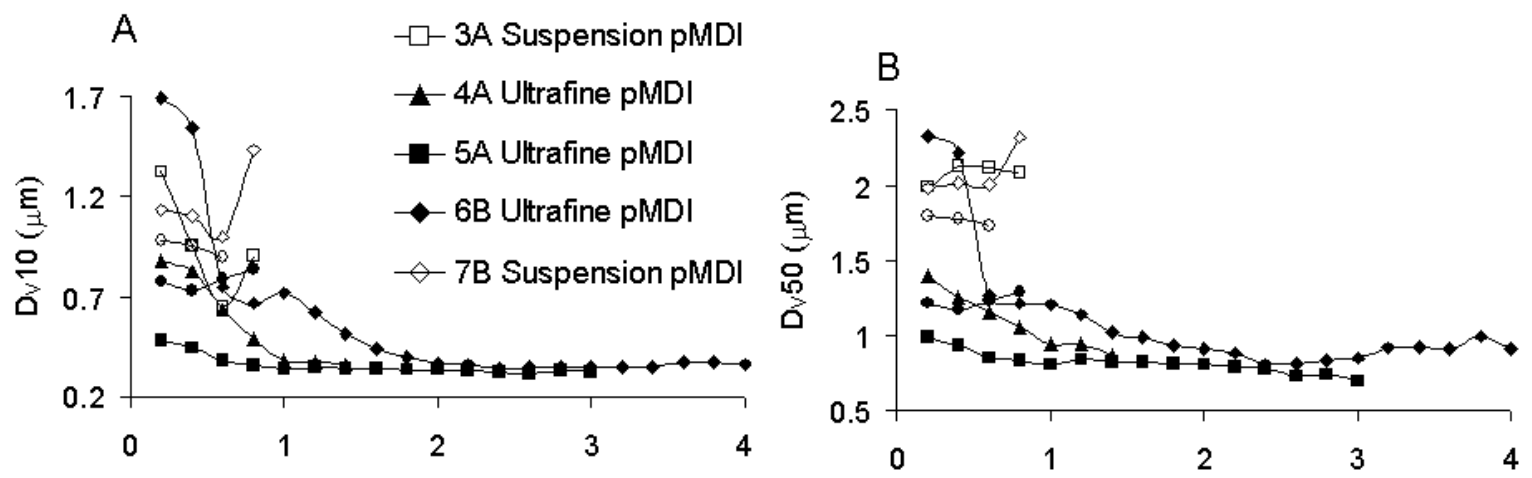

C

Time (s)
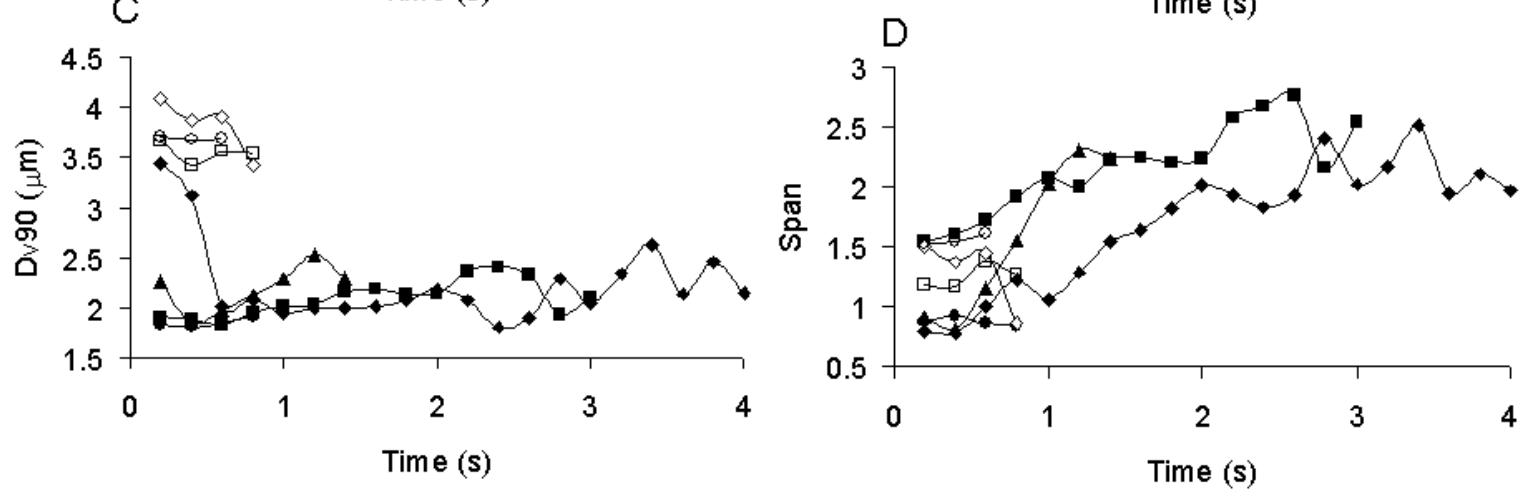
Figure $3 \rightarrow-2 \mathrm{C}$ Ultrafine pMDI+large spacer

$-5 \mathrm{~A}$ Ultrafine $\mathrm{pMDI}+$ large spacer

$\leadsto$ Ultrafine pMDI+large spacer

$\triangle 4$ A Suspemsion pMDI+large spacer

$\smile 6 \mathrm{~B}$ Suspension pMDI+large spacer $\mp 4 \mathrm{~A}$ Ultrafine pMDI+large spacer

$\neg-6 \mathrm{~B}$ Ultrafine pMDI+large spacer

$-\infty 2 \mathrm{C}$ Suspension $\mathrm{pMDI}+$ large spacer

$\square 5 \mathrm{~A}$ Suspension pMDI+large spacer

$\checkmark \checkmark$ Salbutamol pMDI+large spacer
E

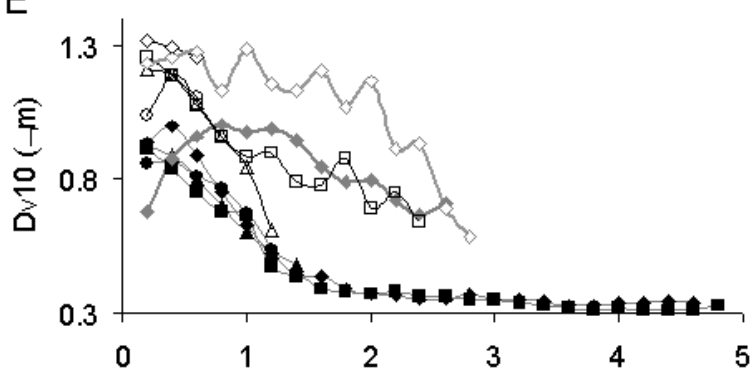

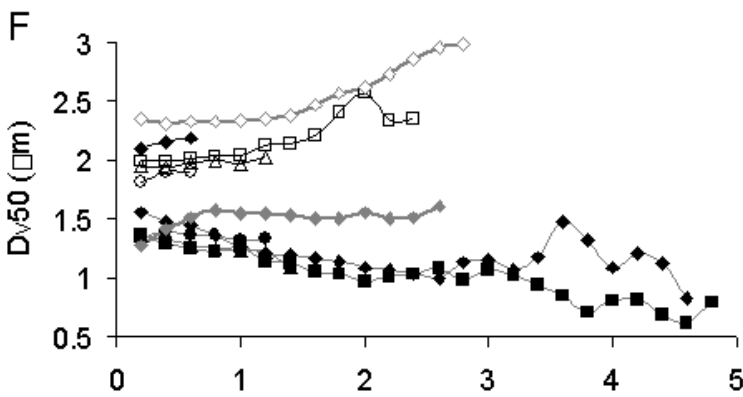
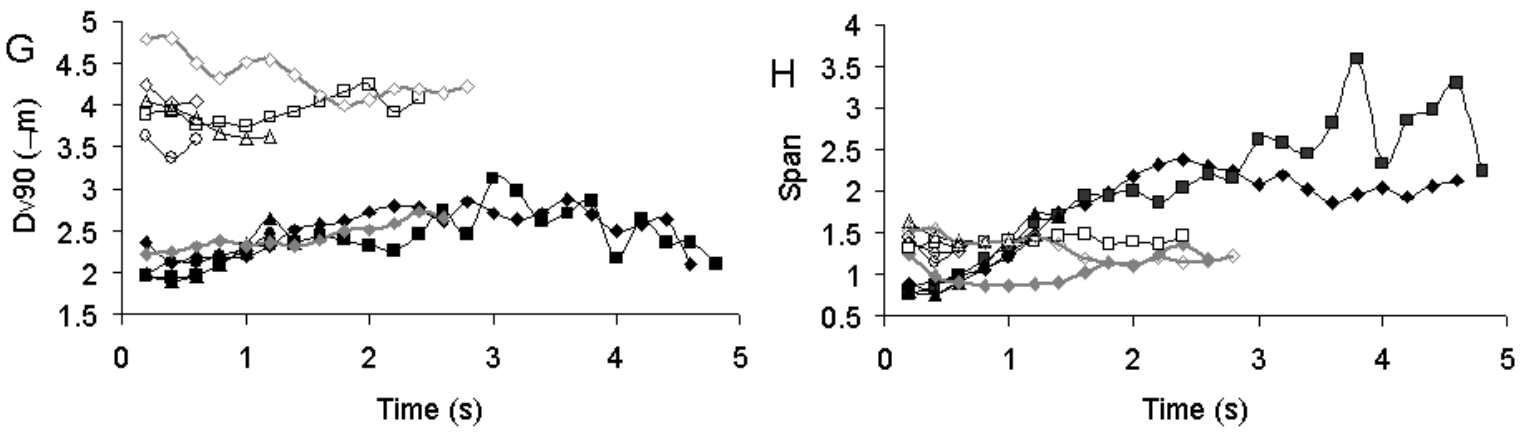
Figure 4


Aerosol Delivery Device

Figure 5
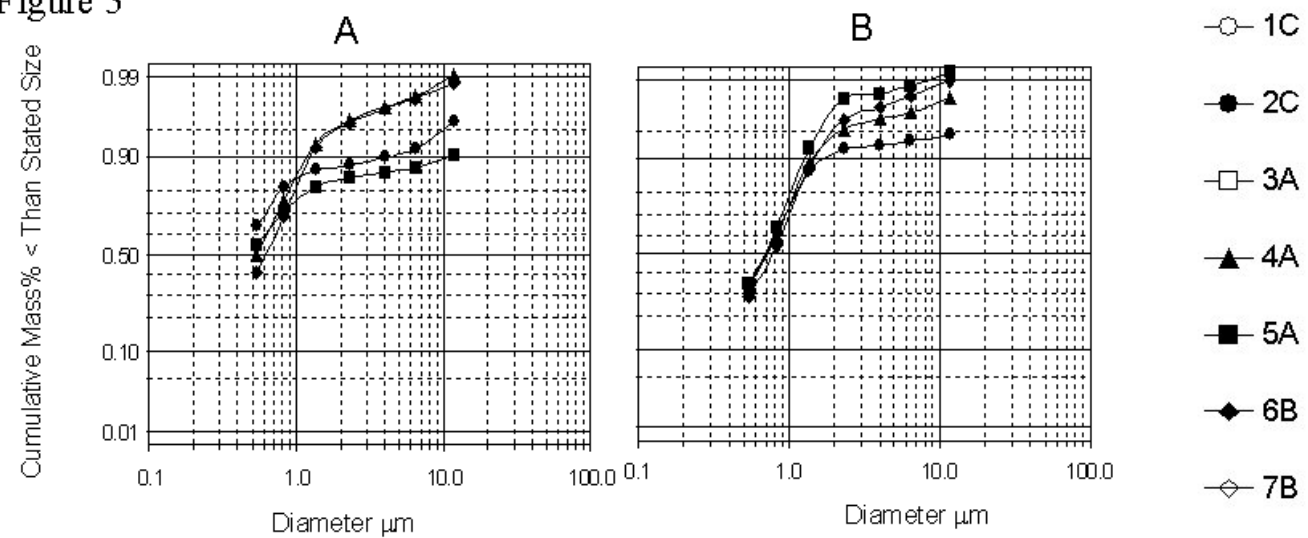

C
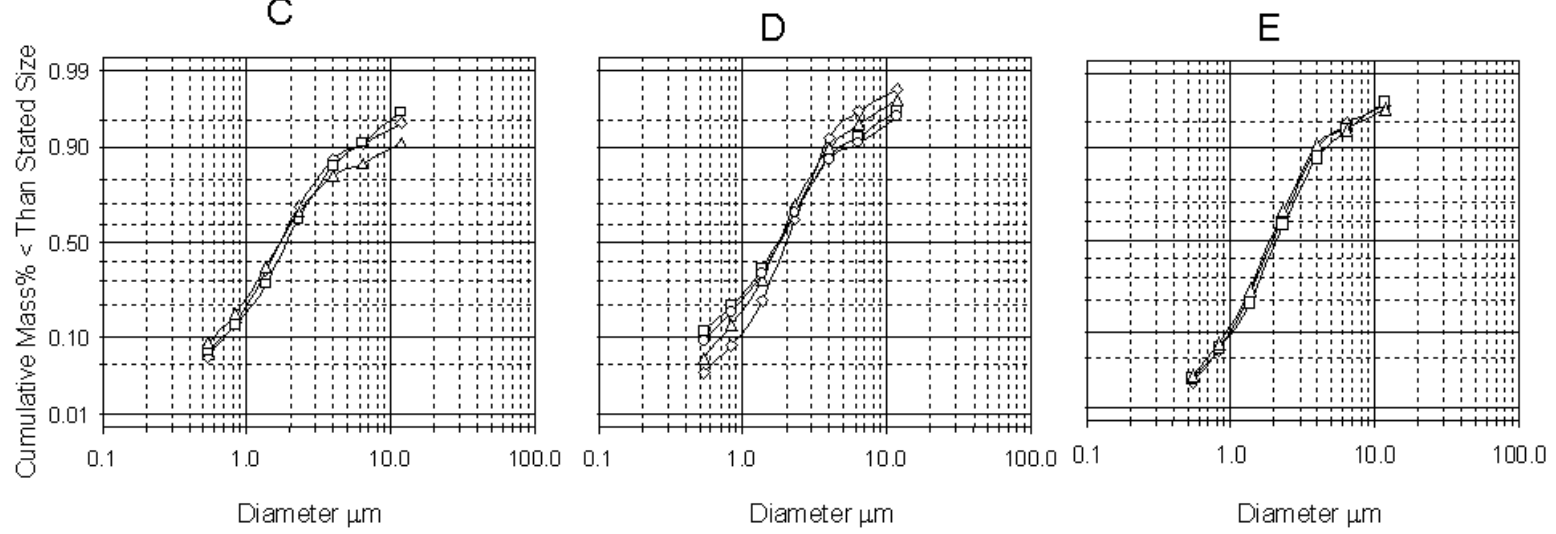
Figure 6
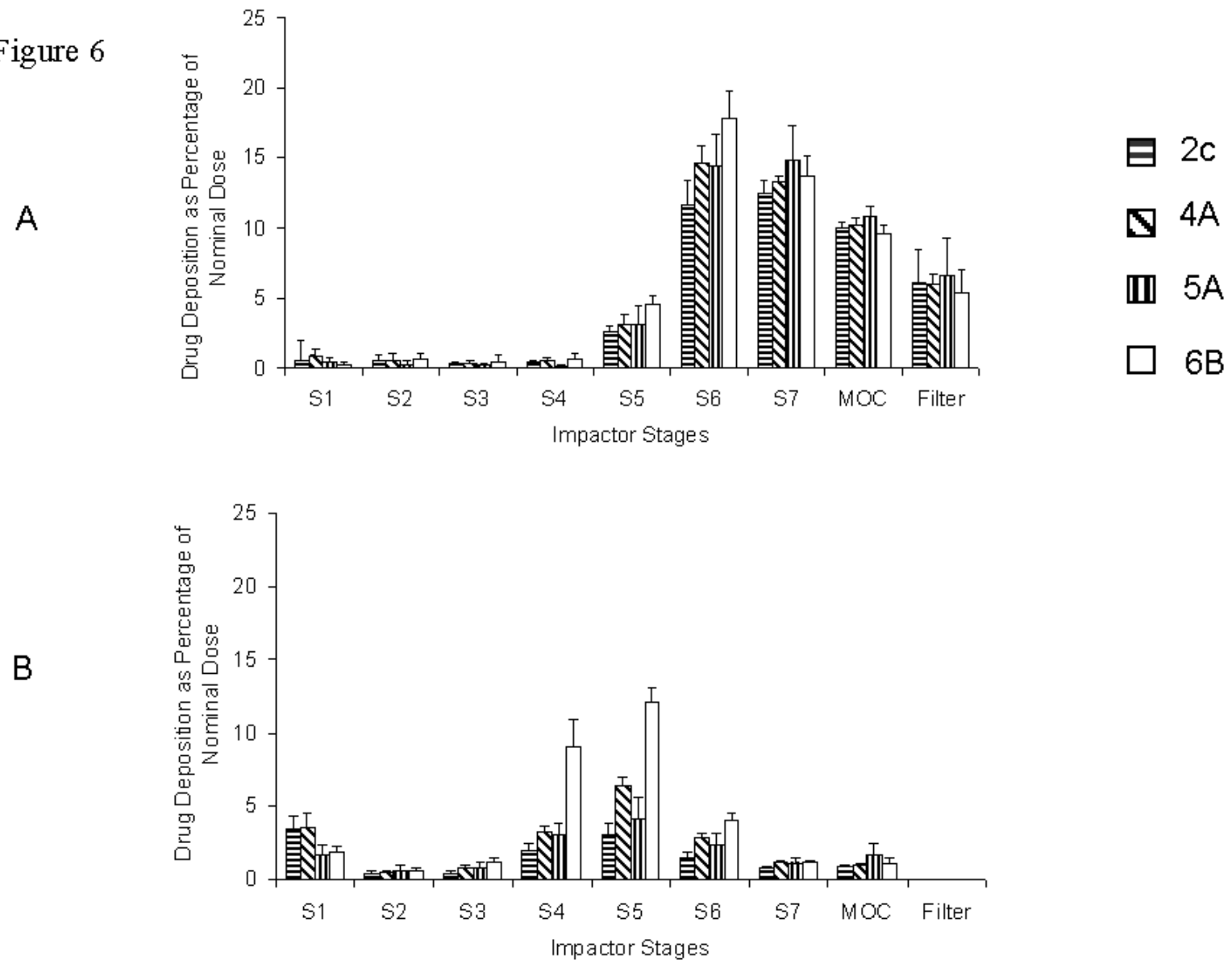
Figure 7

$$
P<0.008 \quad P<0.008 \quad P<0.016 \quad P<0.016
$$

A
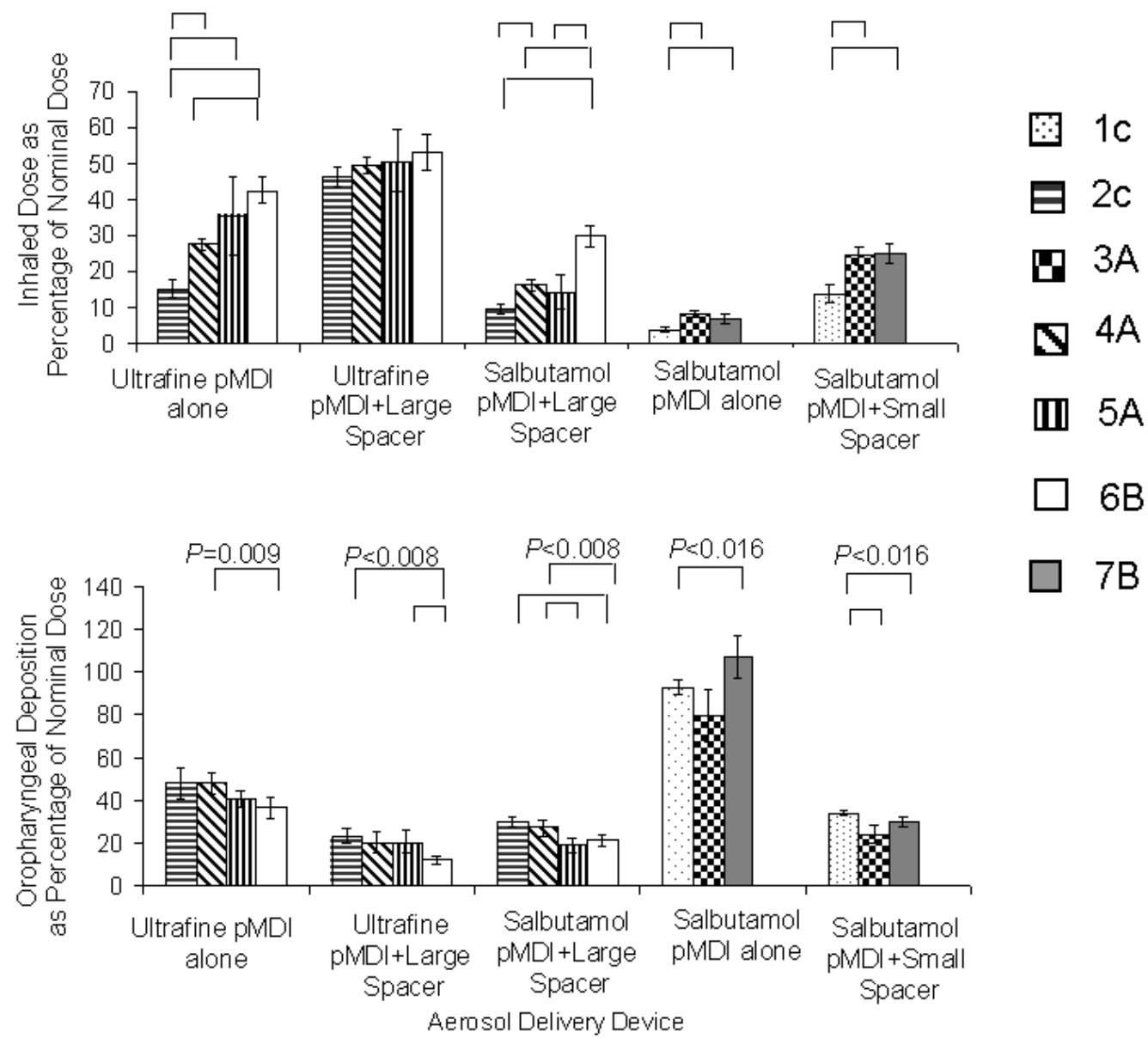


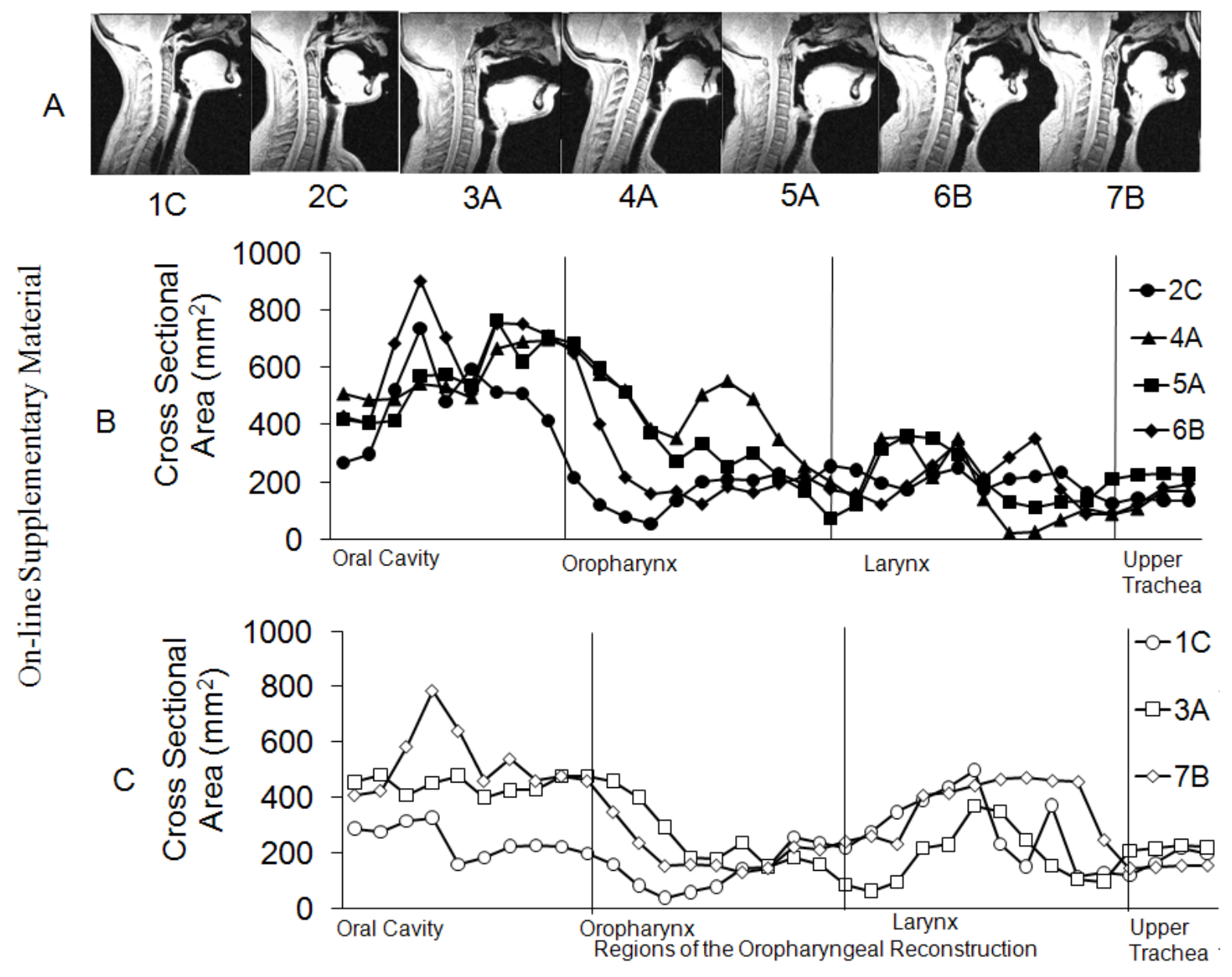

Table 1: The oropharyngeal characteristics and configurations

\begin{tabular}{|l|l|l|l|l|l|}
\hline Oropharyngeal & Oropharyngeal & Oropharyngeal & Oropharyngeal & Gender & Oral cavity \\
Designation $^{\mathrm{a}}$ & Volume/ $\mathrm{cm}^{3}$ & Opening & Centreline & & inlet cross \\
sength/ cm & & & section shape \\
\hline $1 \mathrm{C}$ & 37.6 & $\mathrm{C}$ & 17.1 & $\mathrm{~F}$ & Rectangular \\
\hline $2 \mathrm{C}$ & 53.4 & $\mathrm{C}$ & 18.7 & $\mathrm{~F}$ & Circular \\
\hline $3 \mathrm{~A}$ & 55.9 & $\mathrm{~A}$ & 19.9 & $\mathrm{M}$ & Rectangular \\
\hline $4 \mathrm{~A}$ & 61.8 & $\mathrm{~A}$ & 17.8 & $\mathrm{~F}$ & Circular \\
\hline $5 \mathrm{~A}$ & 68.4 & A & 19.9 & $\mathrm{M}$ & Circular \\
\hline
\end{tabular}




\begin{tabular}{|l|l|l|l|l|l|}
\hline 6B & 75.1 & B & 21.6 & M & Circular \\
\hline 7B & 80.8 & B & 22.3 & M & Rectangular \\
\hline
\end{tabular}

${ }^{\mathrm{a}}$ The designation sequence is: Rank of oropharyngeal volume/oropharyngeal configuration category.

${ }^{\mathrm{b}} \mathrm{A}$ : wide open space; B: a moderate narrowing; C: a marked constriction; F: female; $\mathrm{M}$ : male. 